УДК 617.7-089.5-03:616.89-008.45/.48

https://doi.org/10.26641/2307-0404.2021.1.227948

\title{
Г.С. Дорофеєва
}

\section{ВПЛИВ ОБРАНОГО МЕТОДУ ЗНЕБОЛЕННЯ НА ВИРАЖЕНІСТЬ ПІСЛЯОПЕРАЦІЙНӦ̈ КОГНІТИВНОЇ ДИСФУНКЦІЇ В ПАЦІЕНТІВ ОФТАЛЬМОХІРУРГІЧНОГО ПРОФІЛЮ}

\author{
КП «Дніпропетровська обласна клінічна офтальмологічна лікарня» \\ (дир. - С.Б. Устименко) \\ пл. Соборна, 14, Дніпро, 49005, Україна \\ Д3 «Дніпропетровська медична академія МОЗ України» \\ кафедра анестезіології та інтенсивної терапії \\ (зав. - д. мед. н., проф. Ю.Ю. Кобеляиький) \\ вул. В. Вернадського, 9, Дніпро, 49099, Украӥна \\ $M E$ «Dnipropetrovsk Regional Clinical Ophthalmologic Hospital» \\ Soborna aven., 14, Dnipro, 49005, Ukraine \\ e-mail:kpdokol@ukr.net \\ $S E$ «Dnipropetrovsk medical academy of Health Ministry of Ukraine» \\ V. Vernadsky str., 9, Dnipro, 49044, Ukraine \\ e-mail:das1977@gmail.com
}

\author{
Цитування: Медичні перспективи. 2021. Т. 26, № 1. С. 122-128 \\ Cited: Medicni perspektivi. 2021;26(1):122-128
}

Ключові слова: післяопераційна когнітивна дисфункиія, дексмедетомідин, шкала MMSE

Ключевые слова: послеоперационная когнитивная дисфункиия, дексмедетомидин, икала MMSE

Key words: postoperative cognitive dysfunction, Dexmedetomidine, scale MMSE

Реферат. Влияние выбранного метода обезболивания на выраженность послеоперационной когнитивной дисфункции у пациентов офтальмохирургического профиля. Дорофеева А.С. Снижение когнитивных функиий в послеоперационном периоде приобретает значение в контексте внедрения страховой медицины. $A$ операционный стресс и анестезия являются факторами, которые повышают риск углубления и развития послеоперационных когнитивных дисфункиий. Наиболее уязвимой к действиям общих анестетиков является функциия краткосрочной памяти, функиия внимания, скорость психомоторных когнитивных реакций. В данной работе проведено исследование влияния различных методов анестезии на когнитивные функции у офтальмохирургических пациентов после сквозной кератопластики. Наме особое внимание привлекло использование методики мультимодального обезболивания с сочетанием блокады крыло-небной ямки. Как один из компонентов мультимодального обезболивания нами был использован дексмедетомидин (селективный агонист $\alpha$-адренореиепторов). Седативное действие этого препарата объясняется ингибированием нейронной активности в голубом пятне ствола головного мозга. Также известно, что применение дексмедетомидина для седации пациентов позволило снизить количество использованного фентанила, необходимого для интра- $и$ послеоперационного обезболивания. Наше исследование проводилось на базе КП «ДОКОЛ». Было обследовано 78 пациентов после операџии по сквозной кератопластики возрастом от 18 до 60 лет. Критерии исключения из исследования: наличие сопутствующей патологии, неврологических заболеваний, употребление психотропных веществ и алкоголя менее чем за 6 месячев до проведения исследования. Исследование проводилось с помощью нейропсихологического тестирования: шкала оценки психического статуса (MMSE), шкала лобной дисфункции (FAB). Тестирование проводилось накануне операции, через 6 часов, 24 часа, 7 дней и 21 день. Пациенты были рандомизированы на две группьл. В первую группу - группа $k\left(n_{l}=45\right)$ вошли пациенты, которым анестезиологическое обеспечение было выполнено по следующей схеме: премедикация - ондансетрон 4 мг, дексаметазон 4 мг, кеторолак 30 мг, сибазон 10 мг, фентанил 0,1 мг внутримышечно за 40 минут до вмешательства, индукция - пропофол 2-2,5 мг/кг фракциионо до достижения клинических симптомов наркоза, фентанил 0,005\% 0,1 мг интубация трахеи после релаксаџии на фоне атракурия безилата 0,3-0,6мг/к2 поддержка анестезии: кислородно - севофлурановая смесь $\mathrm{FiO}_{2} 50-55 \%$, севофлуран 1,4-1,8 об.\% на выдохе (11,5 MAC) при потоке не более 1 л/мин. Показатели BIS удерживались на уровне 30-40, в течение оперативного вмешательства использовалось болюсное введение фентанила по 0,1 мг в/в при появлении гемодинамических реакций. Во второй группе - группа $d\left(n_{2}=33\right)$ анестезиологическое обеспечение было выполнено $c$ использованием инфузии дексмедетомидина за 40 мин., ондансетрон 4 мг, дексаметазон 4 мг, кеторолак 30 мг. Индукция, выполнение релаксации и поддержка анестезии выполнялись как в предыдущей группе. Интраоперационный мониторинг паџиентов в обеих группах включал: неинвазивное измерение артериального давления (АД), частоты сердечных сокращений (ЧСС), пульсоксиметрию, определение газов крови: кислорода, углекислого газа и ингаляциионого анестетика на вдохе и выдохе. Контроль глубины наркоза проводился на 
основании BIS- ANI-мониторирования. Использование дексмедетомидина, как компонента мультимодального метода обезболивания, позволяет получить менее выраженные ПОКД за счет снижения количества использованных наркотических средств. Дальнейшее использование комбинации высоко селективных агонистов а2-адренорецепторов в офтальмохирургии является перспективным методом.

\begin{abstract}
The influence of the chosen method of anesthesia on the severity of postoperative cognitive dysfunction in patients with ophthalmic surgery. Dorofeeva G.S. Reduction of cognitive functions in the postoperative period is gaining importance in the context of the insurance medicine introduction. Operational stress and anaesthetization are factors which increase the risk of deepening and developing postoperative cognitive dysfunction. The function of shortterm memory, attention function, and the speed of psychomotor cognitive reactions are the most vulnerable to the action of general anesthetics. The influence of various methods of anesthesia on cognitive functions in ophthalmic surgery patients after end-to-end keratoplasty has been studied in this research work. Dexmedetomidine was used (the selective agonist of $\alpha$-adrenoreceptors) as one of the components of multimodal anaesthetization. The sedative effect of this drug is explained by inhibition of neural activity in the blue spot of the brain stem. Dexmedetomidine is known to be used for sedation of patients. It allowed possibility to reduce the amount of fentanyl which was necessary for intra-and postoperative anaesthetization. Our research was conducted on the basis of ME "DRCOH". 78 patients at the age of 18 to 60 years were examined after end-to-end keratoplasty. Non-inclusion criteria: presence of concomitant pathology, neurological diseases, use of psychotropic substances and alcohol 6 months before the study. The study was conducted using neuropsychological testing: the Mini Mental State Examination (MMSE), the Frontal Assessment Battery (FAB), and Luria's test. Testing was performed before the operation, in 6, 24 hours, 7 and 21 days. Patients were randomized into two groups. The first group - group $k\left(n_{1}=45\right)$ included patients who were provided with anaesthetic management according to the following scheme:premedication — ondansetron $4 \mathrm{mg}$, dexamethasone $4 \mathrm{mg}$, ketorolac $30 \mathrm{mg}$ intravenously, sibazone $10 \mathrm{mg}$, fentanyl $0.1 \mathrm{mg}$ intramuscularly 40 minutes before intervention. Induction of propofol $2-2.5 \mathrm{mg} / \mathrm{kg}$ fractionally to achieve clinical symptoms of anaesthetization, fentanyl - $0.005 \% 0.1 \mathrm{mg}$ tracheal intubation after relaxation on the background of atracuriumbenzylate - 0.3-0.6 mg/kg. Maintaining of anaesthetization: oxygensevoflurane mixture $\mathrm{FiO}_{2} 50-55 \%$, sevoflurane 1,4-1,8 vol.\% on exhalation (1-1. $5 \mathrm{WT}$.) with the flow of no more than $1 \mathrm{l} / \mathrm{min}$. BIS indicators were kept at the level of 30-40, during the surgery, the bolus injection of $0.1 \mathrm{mg}$ of fentanyl was used in the event of hemodynamic reactions. Anaesthetic support was performed using the infusion of dexmedetomidin for 40 minutes, ondansetron $4 \mathrm{mg}$, dexamethasone $4 \mathrm{mg}$, ketorolac $30 \mathrm{mg}$ intravenously in the second group $d\left(n_{2}=33\right)$. Induction, relaxation and maintenance of anaesthetization were performed as in the previous group. Intra-operative monitoring of patients in both groups included: non-invasive measurement of blood pressure (BP), heart rate (HR), pulse oximetry, determination of blood gases (oxygen, carbon dioxide and inhaled anesthetic on inhalation and exhalation). Control of the depth of anaesthetization was performed on the basis of BIS and ANI - monitoring. The use of dexmedetomidinu as the component of a multi-modal method of anaesthetizational al lowed obtaining less pronounced POCD, due to the reduction in the number of used drugs. Further use of the combination of highly selective agonists of $\alpha 2$-adrenoreceptors with regional anaesthetization in ophthalmic surgery is the promising method.
\end{abstract}

Вивчення когнітивної дисфункції в післяопераційному періоді в офтальмохірургічних пацієнтів важлива, проте маловивчена тема [5]. Ця категорія пацієнтів від самого початку має зниження когнітивних функцій внаслідок часткової або повної втрати зору. Зниження когнітивних функцій у післяопераційному періоді набирає значення в контексті впровадження страхової медицини [1]. Операційний стрес та анестезія $\epsilon$ факторами, які підвищують ризик поглиблення та розвитку післяопераційних когнітивних дисфункцій $[2,9]$. Найбільш уразливими до дії загальних анестетиків $є$ функція короткострокової пам'яті, функція уваги, швидкість психомоторних когнітивних реакцій. За даними L. Pengetal (2013 р.), 3 частотою післяопераційних когнітивних дисфункцій (ПОКД) асоціюється рівень інтраопераційної седації $[6,10]$. Водночас $є$ суперечливі дані щодо дії препаратів, що застосовуються для цієї цілі, такі як Севофлюран: за даними X.
Chenetal. (2001 р.), він викликає короткочасне пригнічення 3 повним відновленням протягом 6 годин, інші автори, навпаки, вважають, що цей препарат не має впливу (G. Kadoi, F. Goto, 2007) та надає нейропротективний ефект (В.В. Ліхванцева, 2005, М.I. Неймарк зі співавт., 2007). Сприяє розвитку ПОКД також i порушення циркадного циклу, що виникає після хірургічного лікування, особливо в літніх хворих, що викликає розлад сну і пов'язані з ним зниження секреції мелатоніну [12]. Інтраопераційна інфузія дексмедетомідину значно знижує потребу в опіоїдах, прояви нудоти, блювоти і свербіння порівняно 3 плацебо протягом 48 годин після ПГЕ (Gurbetetal., 2006 Level II) [7, 11]. Комбінація дексмедетомідину з морфіном призводила до значно кращого знеболення, зниження частоти нудоти i значного опіоїд-зберігаючого ефекту (Linetal., 2009 Level II).

Метою нашої роботи було дослідження впливу різноманітних методів анестезії, зокрема 
методики мультимодального знеболення, на когнітивні функції в офтальмохірургічних пацієнтів після наскрізної кератопластики.

\section{МАТЕРІАЛИ ТА МЕТОДИ ДОСЛІДЖЕНЬ}

Дослідження проводилось на базі КП «ДОКОЛ». Було обстежено 78 пацієнтів після операції з наскрізної кератопластики віком від 18

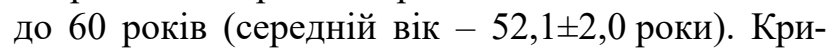
терії виключення 3 дослідження: наявність супутньої патології, неврологічних захворювань, вживання психотропних речовин та алкоголю менше ніж за 6 місяців до проведення дослідження.

Дослідження проводилось за допомогою нейропсихологічного тестування: шкала оцінки психічного статусу (MMSE), шкала лобної дисфункції (FAB) [6]. Тестування проводилось напередодні операції (1 етап) та через 6 годин (2 етап), 24 години (3 етап), 7 діб (4 етап) та 21 добу (5 етап) після оперативного втручання.

Пацієнти були рандомізовані на дві групи. До першої групи - група $\mathrm{k}\left(\mathrm{n}_{1}=45\right)$ увійшли пацієнти, яким анестезіологічне забезпечення було виконано за такою схемою:

- премедикація - ондансетрон 4 мг, дексаметазон 4 мг, кеторолак 30 мг внутрішньовенно, сибазон 10 мг, фентаніл 0,1 мг внутрішньом'язово за 40 хвилин до втручання;

- індукція - пропофол 2-2,5 мг/кг фракційно до досягнення клінічних симптомів наркозу, фентаніл 0,005\% 0,1 мг;

-інтубація трахеї після релаксації на тлі атракурію безилату 0,3-0,6 мг/кг;

- підтримка анестезії: киснево-севофлуранова суміш $\mathrm{FiO}_{2} 50-55 \%$, севофлуран 1,4-1,8 об.\% на видиху (1-1,5 MAC) при потоці не більше 1 л/хв.

Показники BIS утримувалися на рівні 30-40, впродовж оперативного втручання використовувалось болюсне введення фентанілу по 0,1 мг в/в при появі гемодинамічних реакцій.

У другій групі - група $\mathrm{d}\left(\mathrm{n}_{2}=33\right)$ анестезіологічне забезпечення було виконано із використанням інфузії дексмедетомідину за 40 хв., ондансетрон 4 мг, дексаметазон 4 мг, кеторолак 30 мг внутрішньовенно. Індукція, виконання релаксації та підтримка анестезії виконувалися як і попередній групі.

Обидві клінічні групи були статистично зіставними $(\mathrm{p}>0,05)$ за віко-статевими характеристиками. У контрольній групі (k) було 26 (57,8\%) чоловіків і $19(42,2 \%)$ жінок, середній вік $49,5 \pm 2,5$ року; у групі d - $17(51,5 \%)$ чоловіків i $16(48,5 \%)$ жінок $\left(\mathrm{p}=0,583\right.$ за критерієм $\left.\chi^{2}\right)$, середній вік $-55,5 \pm 3,2$ року ( $\mathrm{p}=0,142$ за t-критерієм).
Інтраопераційний моніторинг пацієнтів в обох групах включав: неінвазивне вимірювання артеріального тиску (АТ), частоти серцевих скорочень (ЧСС), пульсоксиметрію, визначення газів крови: кисню, вуглекислого газу та інгаляційного анестетика на вдиху й видиху.

Контроль глибини наркозу та рівня аналгезії проводився на підставі BIS- та ANI-моніторування [8].

Статистичну обробку результатів дослідження проводили за допомогою ліцензійного пакета Statistica v.6.1 (StatsoftInc., США) (№ AGAR909E415822FA). Аналіз кількісних даних проводили 3 урахуванням закону розподілу, оціненого за критеріями Лілієфорса i Шапіро-Уїлка. У випадках нормального закону застосовували середню арифметичну (M), 䜣 стандартну похибку (m), критерій Стьюдента для незалежних вибірок (t), в інших випадках використовували медіану (Me), міжквартильний розмах (25\%; 75\%), критерії Манна-Уїтні (U) та Вілкоксона (W). Вірогідність відмінностей відносних показників оцінювалась за критерієм Хiквадрат Пірсона $\left(\chi^{2}\right)$. Для оцінки взаємозв'язку між різними факторами проводили кореляційний аналіз 3 розрахунком коефіцієнтів кореляції Спірмена (r). Статистично значущим уважалось значення $\mathrm{p}<0,05$ (5\%) [3].

\section{РЕЗУЛЬТАТИ ТА ЇХ ОБГОВОРЕННЯ}

Аналіз показників, що характеризують глибину наркозного сну (індекс BIS) та рівня аналгезії і ноцицепції (індекс ANI), показав їх подібність $(\mathrm{p}>0,05)$ в обох групах дослідження впродовж оперативного втручання (табл.1). Водночас, враховуючи здатність дексмедетомідину потенціювати дію наркотичних аналгетиків, у групі d середня кількість використаного аналгетика (Фентаніл) була в 1,4 разу меншою $3,82 \pm 0,24$ мл проти 5,26 $\pm 0,26$ мл ( $<<0,001)$.

Показники ANI-та BIS- моніторування знаходились у межах оптимальних значень у пацієнтів обох груп. Гемодинамічні значення, параметри газів крові також суттєво не відрізнялись у групах. Стан когнітивних функцій оцінювався за допомогою нейропсихологічного тестування за шкалою лобних дисфункцій (FAB) та короткою шкалою оцінки психічного статусу (MMSE) напередодні операції та у визначені проміжки часу після оперативного втручання (через 6 год., 24 год., на 7 і 21 добу). Динаміка показників когнітивних функцій залежно від етапу дослідження в клінічних групах представлена в таблиці 2. 
Табличя 1

Порівняння середньої кількості використаних наркотичних аналгетиків,

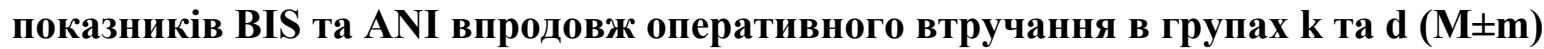

\begin{tabular}{l|c|c|c}
\hline \multicolumn{1}{|c|}{ Група } & Кількість наркотичного аналгетика, мл & Показник АNI, ум.од. & Показник BIS, ум.од. \\
\hline $\mathbf{k}\left(\mathbf{n}_{1}=45\right)$ & $5,26 \pm 0,26 *$ & $60,6 \pm 6,8$ & $36,4 \pm 1,9$ \\
$\mathbf{d}\left(\mathbf{n}_{2}=33\right)$ & $3,82 \pm 0,24 *$ & $58,0 \pm 4,7$ & $36,2 \pm 1,7$ \\
\hline
\end{tabular}

Примітка. ${ }^{*}-\mathrm{p}<0,001$ між групами, в інших випадках $\mathrm{p}>0,05$ (t-критерій).

3 даних таблиці 2 видно, що показники нейропсихологічного тестування за обома шкалами (MMSE таFAB) продемонстрували більш виражене зниження в післяопераційному періоді при використанні «стандартного» методу знеболення (група k). Так, у перші години післяопераційного періоду в групі $\mathrm{k}$ медіана бальної оцінки психічного статусу за шкалою MMSE зменшилась на 7 балів, або на 29,2\% (p<0,001), за шкалою лобної дисфункції $\mathrm{FB}$ - на 6 балів, або на $42,9 \% \quad(\mathrm{p}<0,001)$ від початкового рівня. Наступної доби після втручання відбулось часткове відновлення порушень когнітивних функцій - різниця бальної оцінки 3 вихідним рівнем становила вже 4 бали за шкалами MMSE i $\mathrm{FAB}(\mathrm{p}<0,001) 3$ повним відновленням функцій ( $>0,05)$ тільки до 21 доби обстеження.

Табличя 2

\section{Динаміка показників когнітивних функцій залежно від етапу дослідження в групах k тa d}

\begin{tabular}{|c|c|c|c|c|}
\hline \multirow{2}{*}{ Етап/ метод } & \multicolumn{2}{|c|}{ MMSE, бал, Ме(25\%;75\%) } & \multicolumn{2}{|c|}{ FАВ, бал, Ме(25\%;75\%) } \\
\hline & група $k$ & група d & група k & група d \\
\hline Напередодні & $24(23 ; 25)$ & $25(23 ; 25)$ & $14(13 ; 15)$ & $16(15 ; 16)$ \\
\hline Через 6 год. & $17(15 ; 18) * * ; "$ & $22(21 ; 23) * * ; "$ & $8(7 ; 10) * * ; "$ & $14(13 ; 14) * * ; "$ \\
\hline Через 1 добу & $20(18 ; 21) * * ; "$ & $24(23 ; 25) "$ & $10(9 ; 12) * * ; "$ & $16(15 ; 17) "$ \\
\hline Через 7 діб & $22(20 ; 23) * * ; "$ & $25(24 ; 25) * ; "$ & $13(11 ; 14) * * ; "$ & $16(16 ; 17) * ;$ \\
\hline Через 21 добу & $23(22 ; 25) "$ & $25(25 ; 25) *$ & $14(13 ; 16) "$ & $17(16 ; 18) * * ;$ \\
\hline
\end{tabular}

Примітки: вірогідні відмінності порівняно 3 початковим рівнем: * - p<0,05; ** - p<0,001; вірогідні відмінності порівняно з попереднім етапом: ' - $<<0,05 ;$ " - $<<0,001$ (за W-критерієм Вілкоксона).

У групі d зниження когнітивних функцій у ранньому післяопераційному періоді було менш вираженим - медіанний показник за шкалою MMSE зменшився на 3 бали, або на 12,0\% $(\mathrm{p}<0,001)$, за шкалою $\mathrm{FAB}$ - на 2 бали, або на $12,5 \% \quad(\mathrm{p}<0,001)$ від початкового рівня. Відновлення стану когнітивних функцій до початкового рівня в цій групі відбулось вже наступної доби після оперативного втручання ( $>0,05$ порівняно 3 вихідним рівнем). У подальші терміни спостереження (через 7 і 21 добу) було відмічено подальше покращення показників когнітивних функцій порівняно 3 даними напередодні оперативного втручання (табл. 2). Це явище можливо пояснити як властивостями дексмедетомідину, так i покращенням зору внаслідок проведеного оперативного втручання.

На діаграмі 1 наочно показано, що при використанні дексмедетомідину, як компонента мультимодального знеболення, відбувається нетривале і менш виражене зниження показників когнітивних функцій, ніж при застосуванні «стандартного» анестезіологічного забезпечення. 


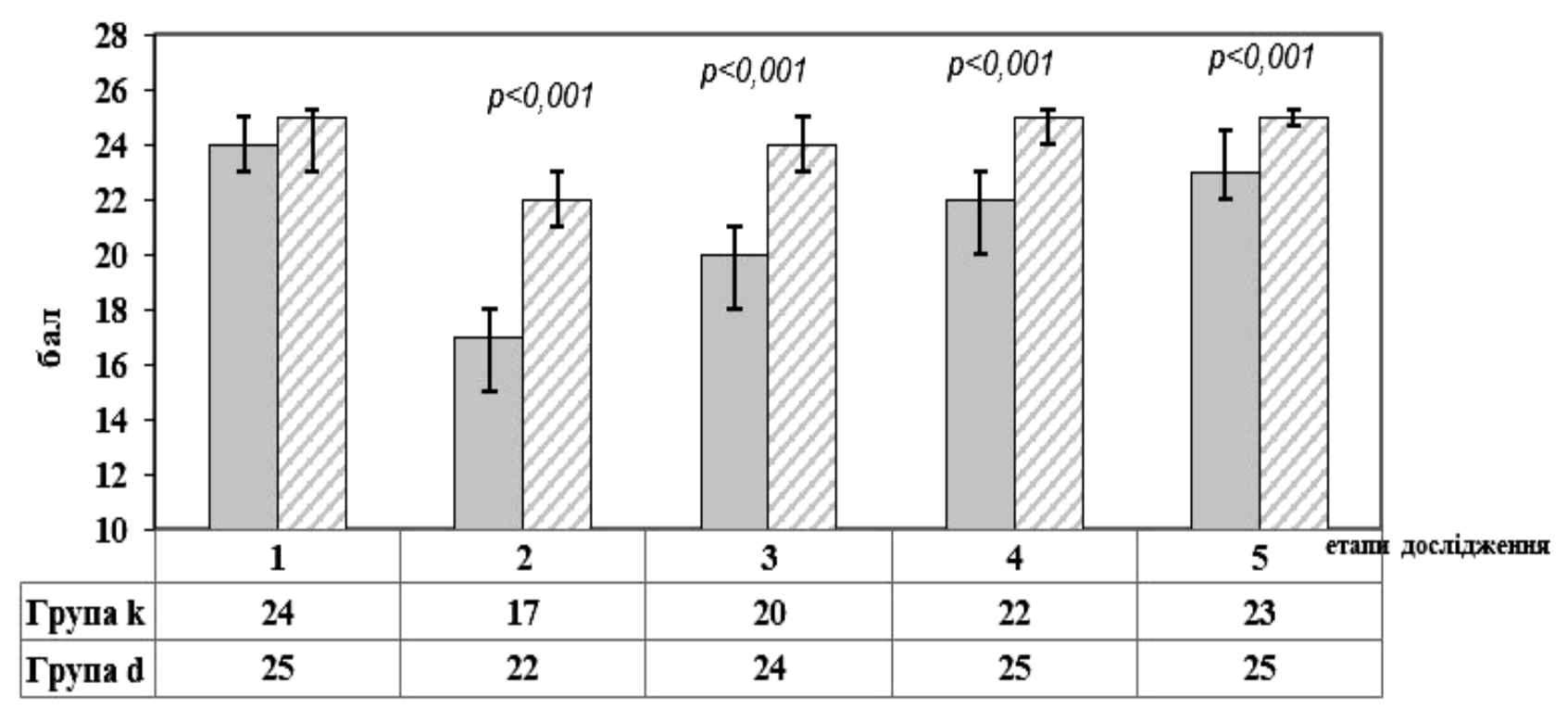

\section{$\square$ Група k $\square$ Фрупа d}

Порівняння середньої бальної оцінки когнітивних функцій за методом МMSE в групах k та d на різних етапах дослідження: наведено Ме (25\%; 75\%); етапи дослідження: 1 - напередодні операції, 2 - через 6 годин, 3 - через 24 години, 4 - через 7 діб, 5 - через 21 добу після оперативного втручання; p - рівень статистичної значущості різниці показників між групами

Таким чином, на підставі оцінювання когнітивних функцій за шкалою лобних дисфункцій (FAB) та короткою шкалою оцінки психічного статусу (MMSE) можливо стверджувати, що відсоток зниження показників та темпи відновлення когнітивних функцій у пацієнтів офтальмохірургічного профілю залежали від обраного методу знеболення. У тих випадках, коли кількість наркотичних аналгетиків (Фентаніл) була менше, то і зниження когнітивних функцій було менше. Це підтверджують зворотні кореляційні зв'язки між кількістю використаного аналгетика і бальною оцінкою когнітивних функцій на різних етапах дослідження: за шкалою MMSE - r=-0,28, $\mathrm{p}<0,05$ через 1 добу, $r=-$ $0,23, \mathrm{p}<0,05$ через 7 діб після втручання; за шкалою $\mathrm{FAB}-\mathrm{r}=-0,40, \mathrm{p}<0,001, \mathrm{r}=-0,38, \mathrm{p}<0,001, \mathrm{r}=-0,33$, $\mathrm{p}<0,01, \mathrm{r}=-0,34, \mathrm{p}<0,01$ через 6 год., 1,7 i 21 добу після втручання відповідно.

Отже, когнітивні функції зазнавали менших змін при застосуванні методу мультимодального знеболення, при якому було застосовано дексмедетомідин. Відновлення стану центральної нервової системи відбувалося швидше (у середньому через 1 добу після оперативного втручання), а в деякої частки пацієнтів (у 30,3\% за шкалою MMSE i в 66,7\% за шкалою $\mathrm{FAB}$ ) ми спостерігали підвищення показників.

\section{ВИСНОВКИ}

1. Використання дексмедетомідину, як компонента мультимодального методу знеболення, дозволяє отримати менш виражені ПОКД за рахунок зниження кількості використаних наркотичних засобів в 1,4 раза.

2. Дексмедетомідин, завдяки властивості потенціювати дію наркотичних аналгетиків (Фентаніл), надає можливість при меншій кількості використаного наркотичного аналгетика зберегти якість анестезії. Показники оцінки глибини наркозу й рівня аналгезії (за допомогою оцінювання BIS- iANI-моніторування) залишались у межах норми.

3. Подальше використання високоселективних агоністів $\alpha 2$-адренорецепторів в офтальмохірургії є перспективним методом. Це клінічно доцільно.

Конфлікт інтересів. Автор заявляе про відсутність конфлікту інтересів. 


\section{СПИСОК ЛІТЕРАТУРИ}

1. Акименко Т. И., Женило В. М., Здирук С. В., Александрович Ю. С. Снижение частоты послеоперационных когнитивных нарушений после ампутации матки при ингаляционной анестезии севофлураном. Альманах клин. медищины. 2018. Т. 46, № 7. С. 699-707. DOI: https://doi.org/10.18786/2072-0505-2018-46-7-699-707

2. Александрович Ю. С., Акименко Т. И., Пшениснов К. В. Послеоперационная когнитивная дисфункция - является ли она проблемой для анестезиолога-реаниматолога? Вест. анестезиологии $u$ реаниматологии. 2019. Т. 16 . № $4 . \quad$ С. 5-11. DOI: https://doi.org/10.21292/2078-5658-2019-16-4-5-11

3. Антомонов М. Ю. Математическая обработка и анализ медико-биологических данных. Киев. 2017. 578 с.

4. Когнитивная дисфункция и общая анестезия: от патогенеза к профилактике и коррекции / А. М. Авезов и др. Неврология, психиатрия, психосоматика. 2016. № 3. С. 101-105.

5. Колесников В. Г. Результати оцінки когнітивних порушень у ранній післяопераційний період у кардіохірургічних пацієнтів 3 артеріальною гіпертензією, оперованих в умовах штучного кровообігу. Медииина неотложных состояний. 2020. Т. 16, № 2. DOI: https://doi.org/10.22141/2224-0586.16.2.2020.203142

6. Особенности когнитивных нарушений при ранениях, полученных в условиях боевых действий / А. А. Криштафор и др. Медицина неотложных состояний. 2018. Т. 81, № 2.

DOI: http://dx.doi.org/10.22141/2224-0586.2.81.2017.99701

7. Age-Related Eye Desease and Cognitive Function / Melanie Varin et al. Ophtalmology. 2019. 09.
8. Ayvardgi A. A, Kobeliatskyi Yu. Yu. ANI-monitoring in assessing the effectiveness of the anesthetic management for plastic surgery of the nose. Emergency medicine. 2018. Vol. 88, No. 1. P. 103-107. DOI: https://doi.org/10.22141/2224-0586.1.88.2018.124975

9. Comparison of Dexmedetomidine,propofol and midazolam for short-term sedation in postoperatively mechanically ventilated neurosurgical patients / V. K. Srivastava et al. J Clin. Diagn. Res. 2014. Vol. 9, No. 8. P. GC04-7.

DOI: https://doi.org/10.7860/JCDR/2014/8797.4817

10. Emery N. Brown, Kara J. Pavone, Marusa Naranjo, Multimodal General Anesthesia: Theory and Practice. Anesth Analg. 2018. Vol. 127, No. 5. P. 1246-1258. DOI: https://doi.org/10.1213/ANE.0000000000003668

11. NaliniKotekar, Anshul Shenkar, Ravishankar Nagaraj, Postoperative cognitive dysfunction - current preventive strategies. Clin. Interv Aging. 2018. Vol. 13. P. 2267-2273. DOI: https://doi.org/10.2147/CIA.S133896

12. Neda Mansouri, Kobra Nasrollahi, Hamidreza Shetabi Prevention of Cognitive Dysfunction after Cataract Surgery with Intravenous Administration of Midazolam and Dexmedetomidine in Elderly Patients Undergoing Cataract Surgery Adv Biomed Res. 2019. Vol. 8, No. 6.

DOI: https://doi.org/10.4103/abr.abr_190_18

13. Study of Feasibility and Safety of Higher-Dose Dexmedetomidine in Special Outpatient Examination of Pediatric Ophthalmology / C. Chen et al. J. Ophthalmol. 2019. 8. Apr. Vol. 2019. P. 2560453.

DOI: https://doi.org/10.1155/2019/2560453

\section{REFERENCES}

1. Akimenko TI, Zhenilo VM, Zdiruk SV, Alexandrovich YuS. [Reducing the incidence of postoperative cognitive impairment after uterine amputation with inhalation anesthesia with sevoflurane]. Almanac of Clinical Medicine. 2018;46(7):699-707. Russian. doi: https://doi.org/10.18786/2072-0505-2018-46-7-699-707

2. Aleksandrovich YuS, Akimenko TI, Pshenisnov KV. [Postoperative cognitive dysfunction - is it a problem for an anesthesiologist-resuscitator?]. Bulletin of anesthesiology and resuscitation. 2019; 16(4):5-11. Russian. doi: https://doi.org/10.21292/2078-5658-2019-16-4-5-11

3. Antonomonov MYu. [Mathematical processing and analysis of biomedical data]. Kyiv; 2017:578. Russian.

4. Avezov AM, Panteleeva MV, Knyazev AV, et al. [Cognitive dysfunction and general anesthesia: from pathogenesis to prevention and correction]. Neurology, psychiatry, psychosomatics. 2016;3:101-5. Russian.

5. Kolesnikov VG. [The results of the assessment of cognitive impairments in the early period of surgery in cardiac patients with arterial hypertension, operated in the minds of a piece blood circulation]. Medicine of emergency conditions. 2020;16(2). Russian. doi: https://doi.org/10.22141/2224-0586.16.2.2020.203142
6. Krishtafor AA, Yovenko IA, Chernenko VG, Klimenko KA, Krishtafor DA. [Features of cognitive impairment in wounds received in combat conditions]. Emergencymedicine. 2018;2(81). doi: http://dx.doi.org/10.22141/2224-0586.2.81.2017.99701

7. Melanie Varin, Marie-Jeanne Keroat, Sylvie Belleville, et al. Age-Related Eye Desease and Cognitive Function. Ophtalmology; 2019 okt. 09.

8. Ayvardgi AA, Kobeliatskyy YuYu. ANI-monitoring in assessing the effectiveness of the anesthetic management for plastic surgery of the nose.Emergency medicine. 2018;1(88):103-7.

doi: https://doi.org/10.22141/2224-0586.1.88.2018.124975

9. Srivastava VK, Agrawal S, Kumar S, et.al. Comparison of Dexmedetomidine,propofol and midazolam for short-term sedation in postoperatively mechanically ventilated neurosurgical patients. J Clin. Diagn. Res. 2014;8(9):GC04-7.

doi: https://doi.org/10.7860/JCDR/2014/8797.4817

10. Emery N, Kara J Pavone, Marusa Naranjo, Multimodal General Anesthesia: Theory and Practice. Anesth Analg. 2018 Nov;127(5):1246-58. doi: https://doi.org/10.1213/ANE.0000000000003668 
11. Nalini Kotekar, Anshul Shenkar, Ravishankar Nagaraj, Postoperative cognitive dysfunction - current preventive strategies. Clin Interv Aging. 2018;13:226773. doi: https://doi.org/10.2147/CIA.S133896

12. Neda Mansouri, Kobra Nasrollahi, Hamidreza Shetabi. Prevention of Cognitive Dysfunction after Cataract Surgery with Intravenous Administration of Midazolam and Dexmedetomidine in Elderly Patients
Undergoing Cataract Surgery Adv Biomed Res. 2019;8:6. doi: https://doi.org/10.4103/abr.abr_190_18

13. Chen C, You M, Li Z, Nie L, Zhao Y, Chen G. Study of Feasibility and Safety of Higher-Dose Dexmedetomidine in Special Outpatient Examination of Pediatric Ophthalmology. J. Ophthalmol. 2019 Apr 8;2560453. doi: https://doi.org/10.1155/2019/2560453

Стаття надійшла до редакції 05.10 .2020 